\title{
Experimental H-type bovine spongiform encephalopathy characterized by plaques and glial- and stellate-type prion protein deposits
}

\author{
Hiroyuki Okada 1*, Yoshifumi Iwamaru', Morikazu Imamura', Kentaro Masujin', Yuichi Matsuura', Yoshihisa Shimizu \\ , Kazuo Kasai', Shirou Mohri ${ }^{1}$, Takashi Yokoyama ${ }^{1}$ and Stefanie Czub²
}

\begin{abstract}
Atypical bovine spongiform encephalopathy (BSE) has recently been identified in Europe, North America, and Japan. It is classified as H-type and L-type BSE according to the molecular mass of the disease-associated prion protein $\left(\mathrm{PrPSC}^{\mathrm{SC}}\right.$ ). To investigate the topographical distribution and deposition patterns of immunolabeled $\mathrm{PrPSC}, \mathrm{H}$ type BSE isolate was inoculated intracerebrally into cattle. H-type BSE was successfully transmitted to 3 calves, with incubation periods between 500 and 600 days. Moderate to severe spongiform changes were detected in the cerebral and cerebellar cortices, basal ganglia, thalamus, and brainstem. H-type BSE was characterized by the presence of PrP-immunopositive amyloid plaques in the white matter of the cerebrum, basal ganglia, and thalamus. Moreover, intraglial-type immunolabeled PrPSc was prominent throughout the brain. Stellate-type immunolabeled PrPSc was conspicuous in the gray matter of the cerebral cortex, basal ganglia, and thalamus, but not in the brainstem. In addition, PrPSc accumulation was detected in the peripheral nervous tissues, such as trigeminal ganglia, dorsal root ganglia, optic nerve, retina, and neurohypophysis. Cattle are susceptible to H-type BSE with a shorter incubation period, showing distinct and distinguishable phenotypes of $\operatorname{PrP}^{S c}$ accumulation.
\end{abstract}

\section{Introduction}

Bovine spongiform encephalopathy (BSE), which belongs to a group of diseases called transmissible spongiform encephalopathies (TSE), is a fatal neurodegenerative disorder of cattle. BSE was first identified in the United Kingdom in 1986 [1], then spread to European as well as North American countries and Japan, and has affected more than 190000 cattle in the world. The infectious agent responsible for TSE is the disease-associated prion protein $\left(\mathrm{PrP}^{\mathrm{Sc}}\right)$, which is thought to be a post-translationally modified form of the host-encoded membrane glycoprotein $\left(\mathrm{PrP}^{\mathrm{C}}\right)$ [2]. According to the protein-only hypothesis, $\operatorname{PrP}^{\mathrm{Sc}}$ is the principal component of the infectious agent.

On the basis of uniform pathology and biochemical profile of the protease-resistant prion protein $\left(\operatorname{Pr} \mathrm{P}^{\text {res }}\right)$ among BSE-affected cattle, it is assumed that BSE in

\footnotetext{
* Correspondence: okadahi@affrc.go.jp

'Prion Disease Research Center, National Institute of Animal Health, 3-1-5

Kannondai, Tsukuba, Ibaraki 305-0856, Japan

Full list of author information is available at the end of the article
}

cattle is caused by only one prion strain. Since 2003, variants of BSE (named atypical BSE) have been detected in Japan, Europe, and North America and classified in at least two groups, namely, H-type and L-type $\mathrm{BSE}$, according to the molecular mass of $\operatorname{PrP}^{\text {res }}$, compared with those of the classical BSE (named C-type BSE) [3]. H-type BSE was first identified in France [4], and L-type BSE, called bovine amyloidotic spongiform encephalopathy (BASE), was first detected in Italy [5]. It is accepted that $\mathrm{C}$-type BSE is caused by the consumption of BSE-contaminated feed, whereas the origins of $\mathrm{H}$-type and L-type BSE remain enigmatic. Hypotheses for the origin of atypical BSE include (1) infection of cattle with different BSE agents; (2) infection of cattle with a non-bovine source or unrecognized forms of infectious TSE agents; (3) genetic mutations in the prion protein gene; and (4) spontaneous or so-called sporadic forms of TSE in cattle, limited to old age, like the sporadic form of human Creutzfeldt-Jakob disease (CJD) [6-10]. However, only one genetic mutation has been found in an H-type BSE case [11]. Sequence analysis of
C Biomed Central

C 2011 Okada et al; licensee BioMed Central Ltd. This is an Open Access article distributed under the terms of the Creative Commons Attribution License (http://creativecommons.org/licenses/by/2.0), which permits unrestricted use, distribution, and reproduction in any medium, provided the original work is properly cited. 
the open reading frame (ORF) of the prion protein gene $(P R N P)$ has not revealed any mutations in atypical BSE cases in France [4], Italy [5], and Canada [12]. Therefore, it seems unrealistic to suggest a genetic origin of atypical BSE [13]. The transmissibility of atypical H-type and L-type BSE to mice [13-18] and cattle [19-22] has been confirmed, and these forms clearly differ from Ctype BSE regarding incubation periods, $\mathrm{PrP}^{\text {res }}$ profiles, protease susceptibility, and spatial distribution patterns of histopathological lesions and immunolabeled $\operatorname{Pr} \mathrm{P}^{\mathrm{Sc}}$ $[3,6,16,20,22]$. Interestingly, C-type [23] and H-type $[14,15]$ BSE isolates were transmissible to wild-type mice already in the first passage, whereas L-type BSE agent failed to transmit in the first passage but was successfully transmitted to wild-type mice in the second passage [17].

Unfortunately, a detailed and all-encompassing analysis of neuropathology and topographical distribution of immunolabeled $\operatorname{PrP}^{\mathrm{Sc}}$ in $\mathrm{H}$-type BSE-affected cattle could not be performed, since only the obex region is routinely sampled for BSE surveillance testing and the remaining brain as well as the carcasses are not available in most countries [3,10,12,13,24-27]. Recently, clinical signs and biochemical properties of experimental German H-type BSE cases have been reported [20]. The primary objective of this study was to investigate the transmissibility of $\mathrm{H}$-type BSE, using a field isolate detected in the active surveillance program in Canada [12]. The secondary objective was to extend the knowledge of the topographical distribution and deposition patterns of immunolabeled $\operatorname{PrP}^{\mathrm{Sc}}$ in $\mathrm{H}$-type BSE.

\section{Materials and methods}

\section{Animal inoculation}

All animal experiments were approved by the Animal Ethical Committee and the Animal Care and Use Committee of National Institute of Animal Health. The Canadian H-type BSE case was of a Charolais cross displaying signs of recumbency prior to euthanasia [12]. By confirmatory immunohistochemistry, the staining pattern was characterized by a predominant reaction in the neuropil (including glial cells) and a relatively low level of intraneuronal, particulate, and stellate immunolabeling in the obex region. The molecular features of $\mathrm{PrP}^{\mathrm{Sc}}$ in cattle were described for the Canadian H-type BSE [12] and C-type BSE [21]. Brain homogenates were prepared in nine volumes of phosphate-buffered saline (PBS, pH 7.4), using a multibead shocker (Yasui Kikai Co., Osaka, Japan). Two female and one neutered 3- to 4-month-old Holstein calves were challenged intracerebrally with $1 \mathrm{~mL}$ of the $10 \%$ brain homogenate prepared from the $\mathrm{H}$-type BSE case. Intracerebral transmission of C-type BSE has previously been reported in cattle [21]. In brief, the inoculum was injected into the midbrain via an 18-gauge 7-cm-long disposable needle (NIPRO, Osaka, Japan), following which the needle was withdrawn from the brain. Two sham-inoculated Holstein calves served as controls; they were euthanized at the age of 27 months.

\section{Tissue processing for histology}

The left brain, including the brainstem and cerebellum, of the H-type BSE case was fixed in 10\% neutral buffered formalin ( $\mathrm{pH} 7.4)$, while the contralateral side was frozen at $-80^{\circ} \mathrm{C}$ for western blot analysis of $\mathrm{PrP}^{\mathrm{Sc}}$. Tissues of C-type BSE for this study were derived from previously reported experimental cases [21]. Coronal slices of the formalin-fixed sample from each animal were cut serially, treated with $98 \%$ formic acid for $60 \mathrm{~min}$ at room temperature (RT) [28], embedded in paraffin wax, sectioned at 4- $\mu \mathrm{m}$ thickness, stained with hematoxylin \& eosin (HE), and used for immunohistochemistry.

The lesion profile was determined in the HE-stained sections by scoring the vacuolar changes in 17 different brain areas as previously described [29]. Selected brain sections were stained with phenol Congo red [30]. In brief, Congo red dye dissolved at $0.2 \mathrm{~g}$ in $100 \mathrm{~mL}$ of distilled water was mixed with $9 \mathrm{~g}$ of $\mathrm{NaCl}$ and subsequently with an equal volume of $100 \%$ ethanol. This mixture was allowed to stand on ice for $10 \mathrm{~min}$. After filtration, phenol (Nacalai Tesque, Kyoto, Japan) was added at $5 \mathrm{~g}$ in $100 \mathrm{~mL}$ of the supernatant, and the $\mathrm{pH}$ was adjusted to around 3.0 by adding glacial acetic acid. The sections were stained in this solution for $1 \mathrm{~h}$. After hematoxylin counterstaining, the sections were examined under a polarizing microscope.

\section{PrP ${ }^{\text {Sc }}$ immunolabeling}

Dewaxed sections were treated with $3 \%$ hydrogen peroxide for $10 \mathrm{~min}$, followed by incubation with $10 \mu \mathrm{g} / \mathrm{mL}$ proteinase $\mathrm{K}(\mathrm{PK})$ at RT for $10 \mathrm{~min}$. Thereafter, the sections were subjected to an antigen retrieval protocol by alkaline hydrolysis at $60^{\circ} \mathrm{C}$ for $10 \mathrm{~min}$ in $150 \mathrm{mM}$ sodium hydroxide [31]. They were incubated with $10 \%$ normal goat serum for $10 \mathrm{~min}$ and then with the following anti-PrP primary antibodies for $60 \mathrm{~min}$ : SAF32, SAF54, SAF84, 12F10, F89/160.1.5, F99/97.6.1, T1 [32], $44 \mathrm{~B} 1$ [33], and 43C5 [33] as the 9 monoclonal antibodies (mAbs) and B103 [34] and T4 [35] as the 2 rabbit polyclonal antibodies (pAbs) (Table 1 ). Working concentrations of the mAbs and pAbs were $1 \mu \mathrm{g} / \mathrm{mL}$ and 5 $\mu \mathrm{g} / \mathrm{mL}$, respectively. Immunolabeling was performed with an anti-mouse or anti-rabbit universal immunoperoxidase polymer (Nichirei Histofine Simple Stain MAX PO (M) or (R); Nichirei, Tokyo, Japan) for $30 \mathrm{~min}$, and the reaction was visualized using 3,3'-diaminobenzidine tetrachloride as the chromogen for $7 \mathrm{~min}$. Finally, the sections were slightly counterstained with Mayer's 
Table 1 Characteristics of the 11 antibodies and the epitope location of the bovine PrP

\begin{tabular}{|c|c|c|c|c|c|c|}
\hline \multicolumn{2}{|c|}{ Antibodies } & \multicolumn{2}{|c|}{ Epitope } & \multirow[t]{2}{*}{ Clonality } & \multirow[t]{2}{*}{ Immunogen } & \multirow[t]{2}{*}{ Source ${ }^{* *}$} \\
\hline & & Location & Type* & & & \\
\hline \multirow[t]{5}{*}{$\mathrm{N}$-terminal region } & SAF32 & $62-92$ & L & Monoclonal & SAF from infected hamster brain & SPI-Bio (Montigny-le-Bretonneux, France) \\
\hline & B103 & $103-121$ & $\mathrm{~L}$ & Polyclonal & Cattle recPrP & FUJIREBIO (Tokyo, Japan) [34] \\
\hline & F89/160.1.5 & 148-155 & L & Monoclonal & Cattle recPrP & VMRD (Pullman, WA, USA) \\
\hline & $\mathrm{T} 1$ & 149-153 & $\mathrm{L}$ & Monoclonal & Mouse recPrP & Dr Tagawa \\
\hline & $12 \mathrm{~F} 10$ & 154-163 & L & Monoclonal & Hamster recPrP & SPI-Bio \\
\hline \multirow[t]{4}{*}{ Core region } & SAF54 & $168-172$ & $\mathrm{~L}$ & Monoclonal & SAF from infected hamster brain & SPI-Bio \\
\hline & $44 \mathrm{~B} 1$ & $168-242$ & DC & Monoclonal & Mouse recPrP & Dr Horiuchi [33] \\
\hline & SAF84 & $175-180$ & L & Monoclonal & SAF from infected hamster brain & SPI-Bio \\
\hline & $43 C 5$ & 175-181 & $L$ & Monoclonal & Mouse recPrP & Dr Horiuchi [33] \\
\hline \multirow[t]{2}{*}{ C-terminal region } & $\mathrm{T} 4$ & $221-239$ & L & Polyclonal & Cattle recPrP & Dr Sata [35] \\
\hline & F99/97.6.1 & 229-235 & L & Monoclonal & Cattle recPrP & VMRD \\
\hline
\end{tabular}

$\mathrm{SAF}$, scrapie-associated fibrils; recPrP, recombinant prion protein

${ }^{*} L$, linear; $D C$, discontinuous

**manufacturer and reference number

hematoxylin. To observe the topographical distribution of $\operatorname{PrP}^{\mathrm{Sc}}$ in the brain with the naked eye, the immunolabeled sections were photographed and viewed with Microsoft PowerPoint.

\section{Western blotting}

The CNS tissues were homogenized in a buffer containing $100 \mathrm{mM} \mathrm{NaCl}$ and $50 \mathrm{mM}$ Tris- $\mathrm{HCl}(\mathrm{pH}$ 7.6). The homogenate was mixed with an equal volume of detergent buffer containing 4\% (w/v) Zwittergent 3-14 (Merck, Darmstadt, Germany), 1\% (w/v) Sarkosyl, 100 $\mathrm{mM} \mathrm{NaCl}$, and $50 \mathrm{mM}$ Tris- $\mathrm{HCl}(\mathrm{pH} 7.6)$ and incubated with $0.25-\mathrm{mg}$ collagenase, followed by incubation with PK (final concentration, $40 \mu \mathrm{g} / \mathrm{mL}$ ) at $37^{\circ} \mathrm{C}$ for $30 \mathrm{~min}$. PK digestion was terminated using $2 \mathrm{mM}$ Pefabloc. The sample was then mixed with 2-butanol:methanol $(5: 1)$ and centrifuged at $20000 \mathrm{~g}$ for $10 \mathrm{~min}$.

$\mathrm{PrP}^{\mathrm{Sc}}$ was extracted from the peripheral nervous, extranervous, and lymphoid tissues by phosphotungstic acid precipitation as described previously [36]. The extracted samples were mixed with a gel-loading buffer containing $2 \%(\mathrm{w} / \mathrm{v})$ sodium dodecyl sulfate (SDS) and boiled for $5 \mathrm{~min}$ before electrophoresis. The samples were then separated by $12 \%$ SDS-polyacrylamide gel electrophoresis (PAGE) and electrically blotted onto a polyvinylidene fluoride (PVDF) membrane (Millipore, Billerica, MA, USA). The blotted membrane was incubated with anti-PrP mAbs 6H4 (Prionics, Schlieren, Switzerland) and SAF84 at RT for $60 \mathrm{~min}$. Signals were developed with a chemiluminescent substrate (SuperSignal; Pierce Biotechnology, Rockford, IL, USA). After PK treatment, some samples were deglycosylated with $\mathrm{N}$-glycosidase F (PNGase F; New England Biolabs, Beverly, MA, USA), according to the manufacturer's instructions.

\section{Polymerase chain reaction (PCR) amplification and DNA sequencing}

In each case, genomic DNA was isolated and purified from the liver using a GenElute mammalian genomic DNA purification kit (Sigma, St. Louis, MO, USA) according to the manufacturer's instructions. The ORF (792 bp) of PRNP was amplified using the primers 5'ATGGTGAAAAGCCACATAG-3' and 5'-CTATCCTACTATGAGAAAAATG-3'. The purified PCR products of the bovine PRNP were directly sequenced using ABI 3100-Avant sequencer (Applied Biosystems, Foster City, CA, USA), with the abovementioned PCR primers. The nucleotide sequences obtained for the 3 challenged calves were aligned using the GENETYX software (GENETYX Co., Tokyo, Japan), with the following GenBank accession numbers: AY367641, AY367642, and AY367643.

\section{Results \\ Clinical signs}

The 3 challenged calves developed initial signs of clinical disease approximately 12 months post challenge, which included disturbance, anxiety, and occasionally low head carriage. After 3-4 months of the onset of the clinical disease, the animals showed loss of body condition. Around 7-10 days prior to euthanasia, the animals developed ataxia of the forelimbs and hindlimbs and myoclonus and were unable to rise. The cattle were euthanized at 507 (case 1, code 7749), 574 (case 2, code 9458), and 598 (case 3, code 0728) days post challenge (mean \pm standard deviation, $559.7 \pm$ 47.2 days). The clinical signs were similar in all the 3 $\mathrm{H}$-type BSE-challenged animals. The animals did not show any change in temperament, such as nervousness or aggression. 


\section{Neuropathology}

Scores for the distribution and severity of vacuolation in the brain were similar among the 3 challenged calves. Vacuolar changes were generally observed in all the brain areas. In general, the vacuoles varied in size. The highest mean lesion scores appeared in the thalamic nuclei and neuropil of the central gray matter of the midbrain, and the lowest scores were found in the caudal cerebral and cerebellar cortices. In the vestibular and pontine nuclei, spongy changes were not as prominent as in the other brainstem nuclei. In the spinal cord of the animals with clinical disease, mild vacuolation was present in the neuropil of the gray matter. The detailed vacuolar lesion profile is shown in Figure 1. Lesion scores for C-type BSE in cattle have been previously described [21].

\section{PrP ${ }^{\text {Sc }}$ immunohistochemistry}

Initially, immunohistochemistry was performed with the C-terminus PrP specific antibody F99/97.6.1. Large amounts of $\mathrm{PrP}^{\mathrm{Sc}}$ were deposited diffusely in the cerebral cortex, basal ganglia, thalamus, hypothalamus, brainstem, and spinal cord of all three challenged animals (Figure 2). The most conspicuous type of $\operatorname{Pr} \mathrm{P}^{\mathrm{Sc}}$ deposition was fine or coarse particulate-type deposition in the neuropil of the gray matter throughout the brain and spinal cord of all the animals (Figures $3 \mathrm{a}$ and $3 \mathrm{~b}$ ). Linear, perineuronal, and intraneuronal types of $\mathrm{PrP}^{\mathrm{Sc}}$ staining, usually detected in C-type BSE-affected cattle, were observed in the cerebral cortex, basal ganglia, thalamus, and brainstem of the $\mathrm{H}$-type BSE-challenged

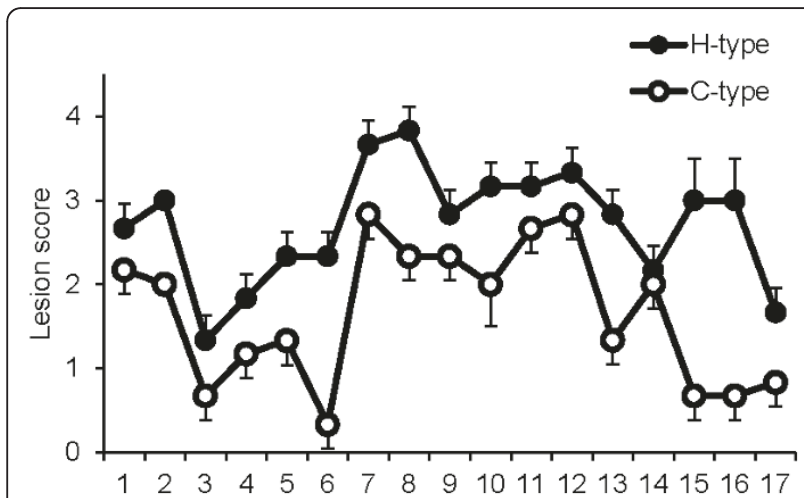

Figure 1 Lesion profile of H-type BSE-challenged cattle in 17 brain areas. The different brain areas indicated are as follows: 1, nucleus of the solitary tract; 2 , nucleus of the spinal tract of the trigeminal nerve; 3 , hypoglossal nucleus; 4, vestibular nuclear complex; 5, cochlear nucleus; 6, cerebellar vermis; 7, central gray matter; 8, superior colliculus; 9, medial geniculate nucleus; 10, hypothalamus; 11, dorsomedial nucleus of the thalamus; 12, ventral intermediate nucleus of the thalamus; 13, frontal cortex; 14, septal nucleus; 15, caudate nucleus; 16, putamen; 17, claustrum. The lesion scores for C-type BSE are taken from a previous study [21]. cattle (Figure 3). The deposition pattern of $\operatorname{PrP}^{\mathrm{Sc}}$ was characterized by the presence of stellate, intraglial, and plaque forms in the brain of the H-type BSE-challenged cattle (Figure 3). Stellate-type $\mathrm{PrP}^{\mathrm{Sc}}$ deposition was predominantly identified in the cerebral cortex, basal ganglia, thalamus, hypothalamus, and hippocampus and often in the cerebellar cortex, but was not visible in the brainstem and spinal cord (Figure 3e). Intraglial-type $\mathrm{PrP}^{\mathrm{Sc}}$ deposition was very consistent throughout the white matter of the central nervous system (CNS) and spinal cord (Figures $3 \mathrm{~h}$ and $4 \mathrm{e}-\mathrm{h}$ ).

$\mathrm{PrP}^{\mathrm{Sc}}$-positive plaques were scattered throughout the cerebral white matter (Figure 4). Some $\operatorname{PrP}^{\mathrm{SC}}$-positive were also detected in the deep cortical layer of the cerebrum, internal capsule of the corpus striatum and thalamic white matter, and cerebellum (Figures $3 \mathrm{f}$ and 4), but were absent from the brainstem and spinal cord. On the basis of the morphology of the cores, as revealed after application of immunohistochemistry, the plaques were classified into unicentric and multicentric types (Figure 4). Unicentric plaques had a single core and were up to $25 \mu \mathrm{m}$ in diameter (Figures $4 \mathrm{a}$ and $4 \mathrm{e}$ ). Multicentric plaques were composed of multiple smaller cores clustered together or a central core surrounded by even smaller plaques or aggregates, varied in shape and could extend up to $40 \mu \mathrm{m}$ in diameter (Figures $4 \mathrm{~b}-4 \mathrm{~d}$ and $4 \mathrm{f}-4 \mathrm{~h}$ ). Both types of plaques were subdivided into two subtypes, that is, those with a dense compact core and others with a pale central core. The dense compact core plaques were less than $20 \mu \mathrm{m}$ in diameter and smaller than the plaques with a pale central core; they were uniformly immunolabeled and were difficult to detect in HE or Congo redstained sections (Figures 4c and 4g). Furthermore, plaques with a pale central core were generally larger than that with a dense compact core and stained pale basophilic or amphophilic with HE and positively with Congo red under polarized light (Figure 4e). The periphery of these plaques looked like a halo unstained with HE and Congo red but well immunolabeled with PrP-specific antibodies. In addition, the granular form of plaque-like deposits, was rarely detected in the deep cerebral cortex, basal ganglia, and thalamic nuclei and not detected in the white matter (Figures $4 \mathrm{~d}$ and $4 \mathrm{~h}$ ). These deposits were not stained with Congo red and were composed of aggregates about $5 \mu \mathrm{m}$ in diameter.

\section{Variability of $\operatorname{PrP}^{\mathrm{Sc}}$ immunolabeling with antibodies}

The H-type cases were further investigated by immunohistochemistry also using a set of other PrP specific antibodies covering the different regions of PrP (Table 1). Results of $\operatorname{PrP}^{\mathrm{Sc}}$ immunolabeling with each antibody are summarized in Table 2 . The immunolabeling intensity of each type of $\operatorname{PrP}^{\mathrm{Sc}}$ varied with the different primary antibodies. The strongest immunolabeling for both 


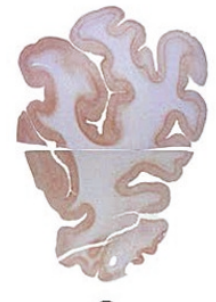

a
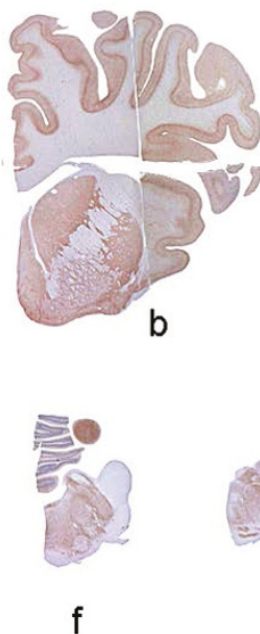

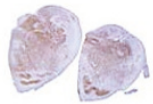

g
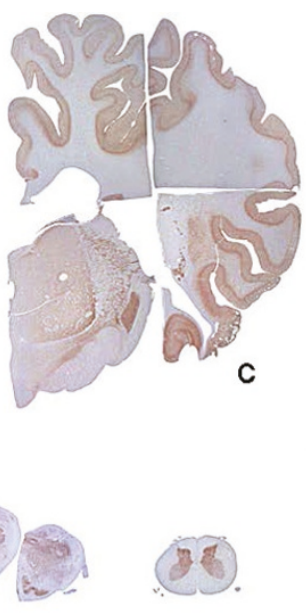

$\mathrm{h}$
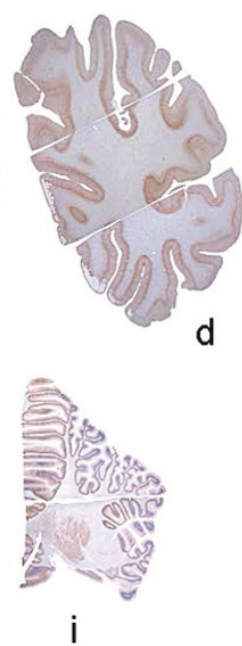

Figure 2 Topographical distribution of $\mathrm{PrP}^{\mathrm{Sc}}$ in the CNS of H-type BSE-challenged cattle. An H-type BSE-challenged case (case 1, code 7749) displays prominent immunolabeling in the cerebral and cerebellar cortices, basal ganglia, thalamus, brainstem, and spinal gray matter, but relatively sparse immunolabeling in the hypothalamus. The 9 different areas indicated are as follows: $a$, frontal cortex; b, septal nucleus; $c$ temporal and parietal cortices and thalamus; d, occipital cortex; e, midbrain; f, pons; g, medulla oblongata at the obex; h, spinal cord; i, cerebellum. The sections show immunohistochemical labeling with mAb F99/97.6.1 and hematoxylin counterstaining.

extracellular and intracellular $\operatorname{PrP}^{\mathrm{Sc}}$ was evident with $\mathrm{mAb}$ F99/97.6.1 and pAb T4, which recognized the C-terminal region of PrP, whereas mAb SAF32 and pAb B103, which recognized the $\mathrm{N}$-terminal region of PrP, showed no or weak immunolabeling. In general, the core-specific antibodies used in this study produced varying degrees of immunolabeling intensity for each extracellular-type $\mathrm{PrP}^{\mathrm{Sc}}$ deposit. Intraneuronal-type $\operatorname{PrP}^{\mathrm{Sc}}$ deposits in $\mathrm{H}$-type BSE showed weaker immunolabeling with the core-specific antibodies than those in C-type BSE. In addition, the core-

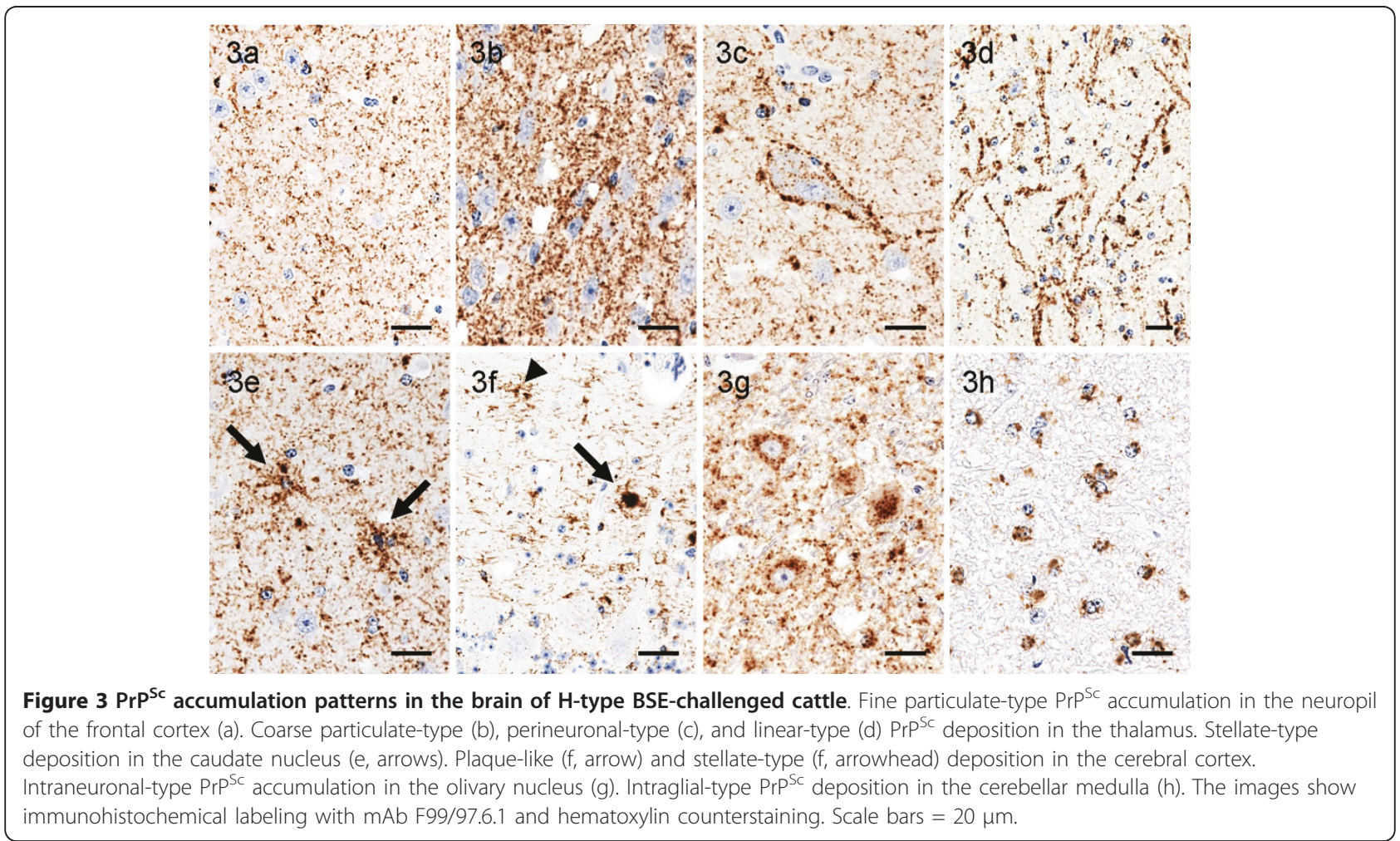




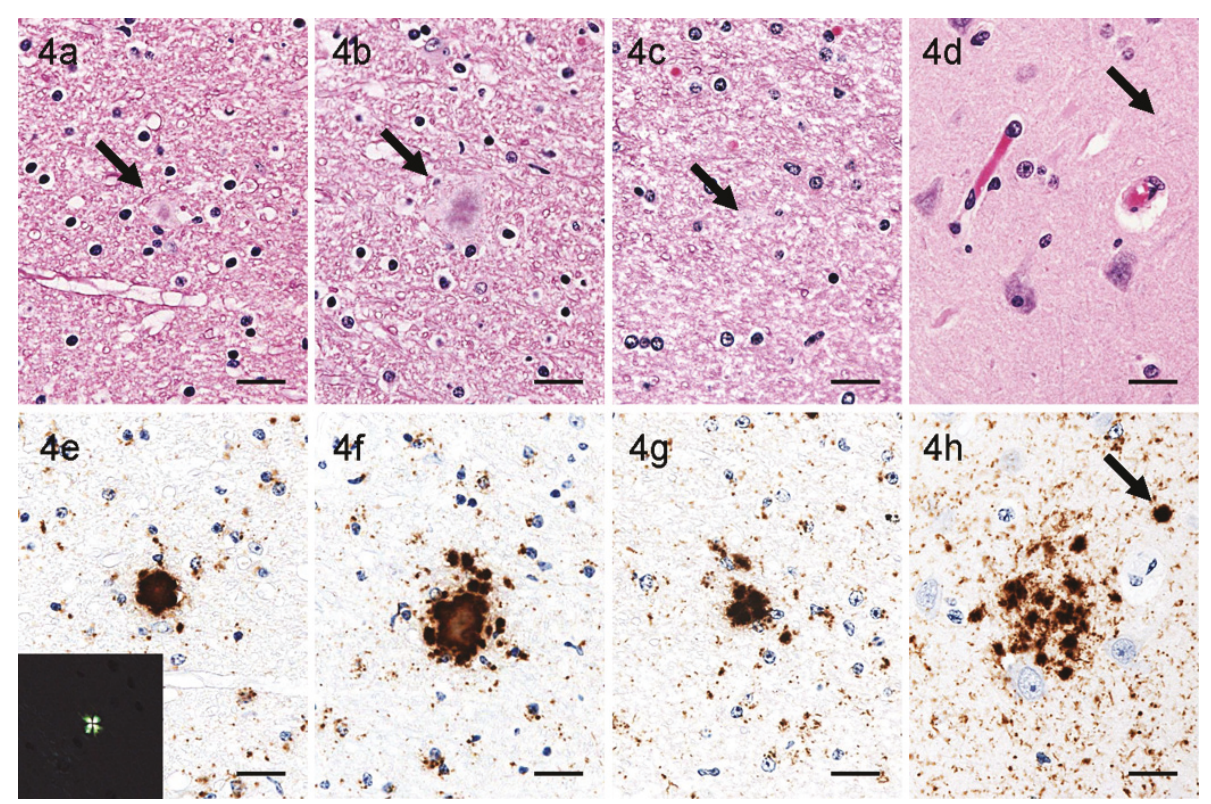

Figure 4 Various types of plaques. Various types of plaques stained with HE (a-d) and immunohistochemical labeling with mAb F99/97.6.1 (eh). Unicentric ( $a$ and e) and multicentric ( $b-d$ and $f-h$ ) cores of plaques (arrows) in the white matter of the thalamus ( $a-c$ and $e-g$ ) and in the deep cortical area of the frontal lobe ( $\mathrm{d}$ and $\mathrm{h}$ ). The inset in the lower left corner of (e) shows an amyloid plaque detected by Congo red staining in the serial section; it shows birefringence under polarized light. Scale bars $=20 \mu \mathrm{m}$.

specific antibodies did not show any immunolabeling for intraglial-type $\operatorname{PrP}^{\mathrm{Sc}}$ deposits.

\section{$\operatorname{PrP}^{\mathrm{Sc}}$ deposition in additional structures}

Positive $\mathrm{PrP}^{\mathrm{Sc}}$ immunolabeling was detected in the trigeminal and dorsal root ganglia, neurohypophysis, retina, and optic nerve. In the neurohypophysis, fine granular $\mathrm{PrP}^{\mathrm{Sc}}$ depositions were detected in the unmyelinated nerve fibers, and intracytoplasmic immunolabeling was detected in the pituicytes. In the retina, intense granular immunolabeling was observed in the ganglion cell layer as well as the inner and outer plexiform layers. In the optic nerve, intraglial immunolabeling was prominent. PrP ${ }^{\mathrm{Sc}}$ was occasionally found in satellite cells and ganglion cells of the trigeminal and dorsal root ganglia. No $\operatorname{PrP}^{\mathrm{Sc}}$ immunolabeling was detected in the lymphoid tissues, including the spleen, tonsils, Peyer's patches, and lymph nodes, in any of the animals.

\section{Western blot analysis}

$\mathrm{PrP}^{\mathrm{res}}$ was detected by western blot analysis using mAbs $6 \mathrm{H} 4$ and SAF84 in all the animals challenged with H-type

Table 2 Comparison of immunolabeling intensities of different PrPSc types between C-type and H-type BSE

\begin{tabular}{|c|c|c|c|c|c|c|c|c|c|c|c|c|c|c|}
\hline \multirow{3}{*}{ Antibody } & \multicolumn{10}{|c|}{ Extracellular PrP ${ }^{S c}$ type } & \multicolumn{4}{|c|}{ Intracellular PrP ${ }^{S c}$ type } \\
\hline & \multicolumn{2}{|c|}{ Particulate } & \multicolumn{2}{|c|}{ Perinuclear } & \multicolumn{2}{|c|}{ Linear } & \multicolumn{2}{|c|}{ Plaque-like } & \multicolumn{2}{|c|}{ Stellate } & \multicolumn{2}{|c|}{ Intraneuronal } & \multicolumn{2}{|c|}{ Intraglial } \\
\hline & C-type & H-type & C-type & H-type & C-type & H-type & C-type & H-type & C-type & H-type & C-type & H-type & C-type & H-type \\
\hline SAF32 & + & - & \pm & - & - & - & + & \pm & + & - & \pm & - & \pm & - \\
\hline B103 & $2+$ & + & + & \pm & $2+$ & \pm & + & + & $2+$ & - & + & - & + & - \\
\hline F89/160.1.5 & $2+$ & $2+$ & $2+$ & $2+$ & $2+$ & $2+$ & $3+$ & $3+$ & $3+$ & $2+$ & $2+$ & + & \pm & - \\
\hline $\mathrm{T} 1$ & $2+$ & + & $2+$ & \pm & $2+$ & + & $2+$ & $3+$ & $2+$ & $2+$ & $2+$ & + & + & - \\
\hline $12 F 10$ & $3+$ & $2+$ & $3+$ & + & $3+$ & + & $3+$ & $2+$ & $3+$ & $2+$ & $3+$ & + & $2+$ & - \\
\hline SAF54 & $2+$ & \pm & $2+$ & - & $2+$ & - & $2+$ & + & $3+$ & + & $2+$ & + & + & - \\
\hline $44 \mathrm{~B} 1$ & $3+$ & $2+$ & $3+$ & $2+$ & $3+$ & $2+$ & $3+$ & $3+$ & $3+$ & $2+$ & $3+$ & $2+$ & + & + \\
\hline SAF84 & $3+$ & $2+$ & $3+$ & + & $3+$ & $3+$ & $3+$ & $3+$ & $3+$ & $3+$ & $3+$ & $2+$ & $2+$ & - \\
\hline $43 C 5$ & $3+$ & $2+$ & $3+$ & + & $3+$ & + & $3+$ & $2+$ & $3+$ & $2+$ & $3+$ & $2+$ & $2+$ & + \\
\hline $\mathrm{T} 4$ & $3+$ & $2+$ & $3+$ & $2+$ & $3+$ & $2+$ & $3+$ & $3+$ & $3+$ & $3+$ & $3+$ & $3+$ & + & $3+$ \\
\hline F99/97.6.1 & $3+$ & $3+$ & $3+$ & $3+$ & $3+$ & $3+$ & $3+$ & $3+$ & $3+$ & $3+$ & $3+$ & $3+$ & $2+$ & $3+$ \\
\hline
\end{tabular}

-, none; \pm , negligible; + , weak; $2+$, distinct; $3+$, strong 
BSE (Figure 5), whereas the control animals were negative for $\operatorname{PrP}^{\text {res }}$. Western blot analysis with $6 \mathrm{H} 4$ showed that the diglycosylated, monoglycosylated, and unglycosylated fragments of PK-treated PrP ${ }^{\text {res }}$ derived from H-type BSE-challenged cattle were more than those of $\mathrm{PrP}^{\mathrm{res}}$ derived from the C-type BSE-affected cattle. On the contrary, the glycoform profiles of $\mathrm{PrP}^{\text {res }}$ derived from both the H-type BSEand C-type BSE-challenged cattle were similar (Figure 5a and $5 \mathrm{c}$ ). With mAb SAF84, a multiple banding pattern was detected from the H-type BSE sample (Figure 5b). After deglycosylation with PNGase F treatment, in addition to $\sim 19 \mathrm{kDa} \operatorname{PrP}^{\mathrm{res}}$ fragment, a $10-12 \mathrm{kDa} \operatorname{PrP}^{\text {res }}$ fragment was detected from the H-type BSE sample (Figure $5 \mathrm{~d})$. This additional $10-12 \mathrm{kDa}$ fragment was not recognized with $6 \mathrm{H} 4$. The molecular size and glycoform patterns of $\mathrm{PrP}^{\text {res }}$ were similar and conserved in the H-type BSE-challenged cattle.

In addition to the brain and spinal cord, $\operatorname{PrP}^{\text {res }}$ was also detected in most of the peripheral nerves, ganglia, optic nerve, retina, hypophysis, and adrenal gland. The intensity of the signal from most of these tissues was, however, barely detectable, but the characteristic triple banding was always detected (Figure 6). No PrP ${ }^{\text {res }}$ signal was detected in the lymphoid tissues of the three challenged calves. The results of the western blot analysis are summarized in Table 3 .

\section{Analysis of $P R N P$}

The mature PrP sequences (amino acids 25-242) of the PRNP ORF in the three challenged animals were compared with the representative bovine PRNP sequence (GenBank accession number: AJ298878) [37]. The PRNP sequence for case 2 (code 9458) was the same as the reference sequence, and that for case 1 (code 7749) was also normal with a synonymous polymorphism at codon 78 (G or A; no amino acid substitution). The 2 animals had 6 copies of the octarepeat region on both the PRNP alleles. The PRNP sequence for case 3 (code 0728) was also normal, and both alleles contained five copies of the octarepeat region.

\section{Discussion}

This study demonstrated successful intraspecies transmission of $\mathrm{H}$-type BSE characterized by a shorter incubation period as compared with C-type BSE [19]. To the best of our knowledge, thus far, neuropathological and immunohistochemical data for H-type BSE have only been reported from the medulla oblongata at the obex in German, United States, and Swedish field cases [10,13,24]. This is related to the fact that only the obex region is sampled for BSE rapid tests and other brain regions are often unavailable due to marked autolysis, limitations in collection infrastructure, or freezing artifacts [10,13,24,25]. This is the first presentation of H-type lesion profiles involving the whole CNS and additional nervous tissues, although of experimentally infected animals.

Incubation periods in the cattle challenged with the Canadian H-type BSE (mean period, 18 months) were two months longer than those reported in cattle

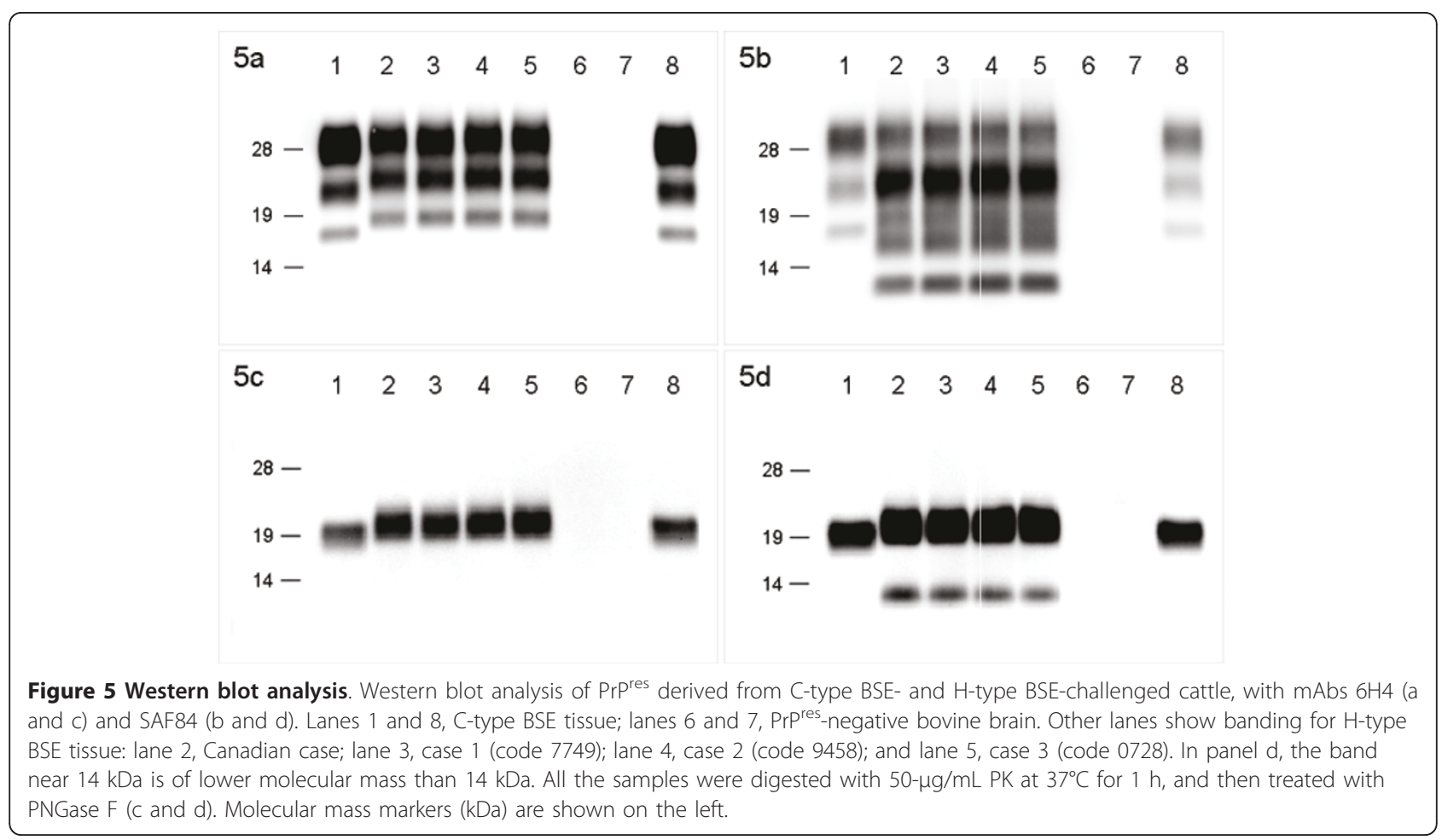




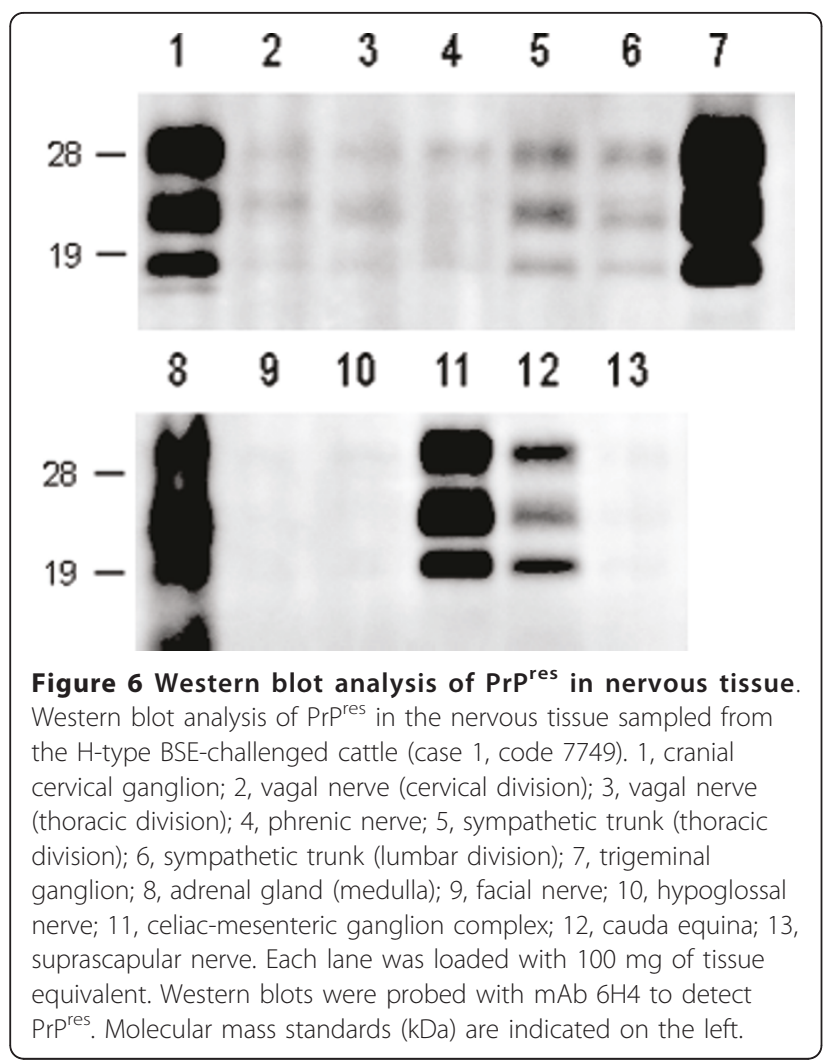

challenged with German H-type BSE [20]. This difference in incubation periods has several potential explanations, which include differences in agents tested, inoculum titers, and breeding conditions. Infectivity titer issues might be resolved by comparing second-passage infection experiment results.

Spongy changes were generally present in the gray matter throughout the brain and spinal cord, but were more conspicuous in the cerebral cortices, thalamus, hypothalamus, and midbrain. In most brain areas, vacuoles were generally detected in the neuropil and only occasionally in the neurons. The spatial distribution pattern of spongiform changes and immunolabeled $\mathrm{PrP}^{\mathrm{Sc}}$ in the brain of an H-type BSE-infected Zebu, analyzed with $\mathrm{N}$-terminal-specific $\mathrm{mAb} \mathrm{P} 4$ and $\mathrm{C}$-terminalspecific mAb F99/97.6.1, was similar to that in C-type BSE cases [38]. In natural and experimental C-type BSE cases, spongiform lesions are consistently distributed throughout the brain, but overall, the lesions in the thalamus and brainstem including the midbrain and medulla oblongata at the obex are more severe than those in the cerebral cortices $[29,39]$. The results of the present study indicate that the vacuolar lesion score of the H-type BSE-challenged cattle was higher than that of C-type BSE-affected cattle [19,29,40,41]. Moreover, the topographical distribution of $\mathrm{PrP}^{\mathrm{Sc}}$ in the brain of
Table 3 Immunohistochemical and western blot analyses of $\mathrm{PrP}^{\mathrm{SC}}$ in tissue samples obtained from cattle intracerebrally challenged with $\mathrm{H}$-type BSE

\begin{tabular}{|c|c|c|c|c|c|c|}
\hline \multirow[t]{3}{*}{ Tissue } & \multicolumn{6}{|c|}{ Case code } \\
\hline & \multicolumn{2}{|c|}{7749} & \multicolumn{2}{|c|}{9458} & \multicolumn{2}{|c|}{0728} \\
\hline & $\mathrm{IHC}$ & WB & $\mathrm{IHC}$ & WB & $\mathrm{IHC}$ & WB \\
\hline \multicolumn{7}{|l|}{ Central nervous system } \\
\hline Cerebral cortex & + & + & + & + & + & + \\
\hline Obex & + & + & + & + & + & + \\
\hline Cerebrum & + & + & + & + & + & + \\
\hline Spinal cord & + & + & + & + & + & + \\
\hline \multicolumn{7}{|l|}{ Peripheral nervous system } \\
\hline Cauda equina & + & + & + & + & + & + \\
\hline Dorsal root ganglia & + & + & + & + & + & + \\
\hline Trigeminal ganglia & + & + & + & + & + & + \\
\hline Cranial cervical ganglia & - & + & - & + & - & + \\
\hline Stellate ganglia & - & + & - & + & - & + \\
\hline Sympathetic trunk & - & + & - & + & - & + \\
\hline Celiac-mesenteric ganglion complex & - & + & - & + & - & + \\
\hline Vagus nerve & - & + & - & + & - & + \\
\hline Facial nerve & - & + & - & + & - & - \\
\hline Hypoglossal nerve & - & + & - & + & - & - \\
\hline Phrenic nerve & - & + & - & + & - & + \\
\hline Accessory nerve & - & - & - & + & - & + \\
\hline Suprascapular nerve & - & + & - & + & - & + \\
\hline Brachial plexus & - & + & - & + & - & + \\
\hline Median nerve & - & + & - & + & - & + \\
\hline Radial nerve & - & + & - & + & - & + \\
\hline Sciatic nerve & - & + & - & + & - & + \\
\hline Tibial nerve & - & + & - & + & - & + \\
\hline Optic nerve & + & + & + & + & + & + \\
\hline Retina & + & + & + & + & + & + \\
\hline Pituitary gland & + & + & + & + & + & + \\
\hline Adrenal gland & - & + & - & + & - & + \\
\hline
\end{tabular}

ymphoid tissues

Spleen

Tonsils (palatine, pharyngeal, lingual)

Thymus

Parotid lymph node

Mandibular lymph node

Lateral retropharyngeal lymph node

Superficial cervical lymph node

Brachiocephalic lymph node

Axillary lymph node

Superficial inguinal lymph node

Subiliac lymph node

Popliteal lymph node

Hepatic lymph node

Internal iliac lymph node

External iliac lymph node

Mesenteric lymph node

$\mathrm{IHC}$, immunohistochemistry; WB, western blotting; +, positive for $\mathrm{PrP}^{\mathrm{Sc}}$; negative for PrPSc 
BSE-infected sheep is similar irrespective of the different challenge routes such as intracerebral, intravascular, or intraperitoneal route [42], suggesting common patterns of neuroinvasion and CNS spread [43]. On the contrary, the minor differences detected in the distribution of $\mathrm{PrP}^{\mathrm{Sc}}$ in the brain between deer that are orally and intracerebrally infected with BSE may be due to differences in the routes of infection [44].

The immunolabeling patterns of $\mathrm{PrP}^{\mathrm{Sc}}$ in the cattle affected with $\mathrm{H}$-type BSE were characterized by the presence of both $\mathrm{PrP}^{\mathrm{Sc}}$-positive plaques and intraglial- and stellate-type $\operatorname{PrP}^{\mathrm{Sc}}$ accumulations in the brain. Severe intraneuronal- and intraglial-type $\operatorname{PrP}^{\mathrm{Sc}}$ accumulations as well as plaque-like $\operatorname{PrP}^{\mathrm{Sc}}$ aggregates with the absence of stellate-type $\operatorname{PrP}^{\mathrm{Sc}}$ deposition have been reported in the obex region of H-type BSE-affected animals [10,13]. These immunohistochemical features were detected in the obex region and coincided with those observed in the present study. However, neither amyloid plaques nor stellate-type $\operatorname{PrP}^{\mathrm{Sc}}$ depositions have been reported in $\mathrm{H}$ type BSE-affected cattle, most likely due to their limitation to the medulla oblongata at the obex $[8,10,13,24]$.

Two different types of plaques were found in this study: unicentric and multicentric PrP plaques. Most of these plaques were uniformly immunopositive for $\operatorname{PrP}$, with a dense non-Congophilic core. The plaques that had a pale central core with a Congophilic reaction were less frequent. It has been suggested that Congophilic plaques may correspond with the late stage of plaque formation, whereas non-Congophilic plaques coincide with the early stage of CJD and Gerstmann-SträusslerScheinker syndrome [45]. The 2 types of $\mathrm{PrP}^{\mathrm{Sc}}$-positive plaques-unicentric and multicentric-have been described in L-type BSE $[5,19,46]$. Our results indicate that the presence of $\mathrm{PrP}^{\mathrm{Sc}}$ plaques in the forebrain but not in the brainstem is one of the neuropathological features in cattle affected with atypical BSE. In addition, glial-type $\operatorname{PrP}^{\mathrm{Sc}}$ deposition in the white matter throughout the brain seems to be a characteristic feature of $\mathrm{H}$ type BSE in cattle, as supported by identical findings in German and Swedish H-type BSE field cases [10,13].

Extracellular $\mathrm{PrP}^{\mathrm{Sc}}$ was immunolabeled with $\mathrm{N}$-terminal-, core-, and C-terminal-specific antibodies, but intracellular $\operatorname{PrP}^{\mathrm{Sc}}$ did not show immunoreactivity to the $\mathrm{N}$-terminal-specific anti-PrP antibodies $[47,48]$. Intracellular $\mathrm{PrP}^{\mathrm{Sc}}$ has markedly diminished immunoreactivity to N-terminal-specific anti-PrP antibodies [47]. However, N-terminal-specific $\mathrm{mAb} \mathrm{P} 4$, which recognizes an epitope at bovine PrP residues 101-107, showed intraneuronal $\mathrm{PrP}^{\mathrm{Sc}}$ immunolabeling in sheep affected with C-type BSE [47] and in Zebu affected with H-type BSE [38]. These results indicate that the epitope region for either mAb P4 or core-specific anti-PrP antibodies is located upstream of an intracellular truncation site
$[38,48]$. The differences in intracellular $\mathrm{PrP}^{\mathrm{Sc}}$ truncation sites between sheep scrapie and ovine BSE [47] as well as between C-type BSE and H-type BSE [38] most probably depend on the strain and the tissues and cells [47]. The intensity and patterns of $\operatorname{PrP}^{\mathrm{Sc}}$ immunolabeling varied with the different anti-PrP antibodies used, and the difference in the $\operatorname{PrP}^{\mathrm{Sc}}$ immunohistochemical labeling results might be related to the application of different technical protocols, especially antigen retrieval methods [49-51].

The western blot profiles of $\operatorname{PrP}^{\text {res }}$ for the H-type BSEchallenged cattle and the Canadian H-type BSE-infected brain homogenate used as inoculum were indistinguishable. Results of previous studies prove that $\mathrm{H}$-type BSE isolates have distinct biological and biochemical properties compared with C-type and L-type BSE isolates $[3,52,53]$. The $\operatorname{PrP}^{\text {res }}$ in H-type BSE, as detected by mAb SAF84 recognizing the C-terminus of PrP, was thought to be composed of 2 fragments with molecular masses of $19 \mathrm{kDa}$ and 10-12 kDa, possessing a different cleavage site in the N-terminal region with PK digestion [53]. The higher molecular mass of the unglycosylated $\operatorname{PrP}^{\text {res }}$ molecules, which included an additional 10-12 kDa fragment, in the Canadian H-type BSE case was maintained in the challenged animals. These unique molecular features of PrP in H-type BSE are also well preserved in transgenic and wild type mice [16,53]. In addition, a distinct $10-12 \mathrm{kDa}$ fragment detected with C-terminal-specific antibodies in H-type BSE might be associated with the presence of PrP plaques [53].

Although $\operatorname{PrP}^{C}$ glycosylation seems to play a critical role in the maintenance of strain-dependent prion neurotropism [54,55], a recent study has demonstrated that $\mathrm{PrP}^{\mathrm{Sc}}$ glycosylation is not required for the maintenance of strain-specific neurotropisms [56]. Strain-dependent prion neurotropism is currently unknown, but several possibilities have been indicated [56]. Moreover, a local difference in the $\operatorname{PrP}^{\mathrm{Sc}}$ replication rate may be attributed to a high degree of neurotropism in H-type BSE similar to that observed in C-type BSE [57].

Since 2003, sporadic and discontinuous occurrence of atypical BSE has been detected in Europe, North America, and Japan. Although, till date, the origin and frequency of atypical BSE is unknown, a high prevalence is found in older cattle over the age of eight years. This is the result of the active surveillance programs using rapid screening tests, with the exception of a Zebu case [38]. It has been reported that H-type BSE can be the result of a naturally occurring, heritable variant caused by glutamic acid/lysine polymorphism at codon 211 of the bovine PRNP gene (E211K) [11,58]. However, our cases, although experimentally challenged via the intracranial route, and the original Canadian H-type BSE field case $[11,58]$ developed the disease without the 
novel mutation E211K within PRNP. Therefore, atypical BSE seemed to be sporadic rather than inherited with a higher risk in fallen stock than in healthy slaughtered cattle $[8,13,25]$, suggesting that young adult cattle affected with atypical BSE might be dormant carriers. Further studies are required to determine the epidemiological significance and origin of atypical BSE.

The present study demonstrated successful intraspecies transmission of H-type BSE to cattle and the distribution and immunolabeling patterns of $\operatorname{PrP}^{\mathrm{Sc}}$ in the brain of the H-type BSE-challenged cattle. TSE agent virulence can be minimally defined by oral transmission of different TSE agents (C-type, L-type, and H-type BSE agents) [59]. Oral transmission studies with H-type BSEinfected cattle have been initiated and are underway to provide information regarding the extent of similarity in the immunohistochemical and molecular features before and after transmission. In addition, the present data will support risk assessments in some peripheral tissues derived from cattle affected with H-type BSE.

\section{Acknowledgements}

We thank Dr Yuichi Tagawa (National Institute of Animal Health) for providing the anti-prion mAb T1 and Dr Motoshi Horiuchi (Graduate School of Veterinary Medicine, Hokkaido University) for providing mAbs 44B1 and 43C5. Expert technical assistance was provided by Mutsumi Sakurai, Miyo Kakizaki, Junko Endo, Noriko Amagai, Tomoko Murata, Naomi Furuya, Naoko Tabeta, Nobuko Kato, and the animal caretakers. This work was supported by grants from the BSE and other Prion Disease Control Projects of the Ministry of Agriculture, Forestry and Fisheries of Japan and from the Canadian Food Inspection Agency.

\section{Author details \\ ${ }^{1}$ Prion Disease Research Center, National Institute of Animal Health, 3-1-5 Kannondai, Tsukuba, Ibaraki 305-0856, Japan. ${ }^{2}$ Canadian and OIE Reference Laboratories for BSE, Canadian Food Inspection Agency Lethbridge Laboratory, Lethbridge, Alberta, Canada.}

\section{Authors' contributions}

Conception and design of experiments: TY and HO. Conduction of experiments: $\mathrm{HO}, \mathrm{YI}, \mathrm{MI}, \mathrm{KM}$, and YM. Intracerebral inoculation of H-type BSE isolate and collection of samples from $\mathrm{H}$-type BSE-infected cattle: $\mathrm{YI}, \mathrm{HO}, \mathrm{MI}$, KM, YS, and KK. Manuscript draft preparation and data analysis: $\mathrm{HO}, \mathrm{Yl}, \mathrm{MI}$, and YM. Participation in scientific discussion of the results: SC. Study supervision: SM. All the authors have read and approved the final manuscript.

\section{Competing interests}

The authors declare that they have no competing interests.

Received: 5 January 2011 Accepted: 23 June 2011

Published: 23 June 2011

\section{References}

1. Wells GA, Scott AC, Johnson $C T$, Gunning RF, Hancock RD, Jeffrey $M$, Dawson M, Bradley R: A novel progressive spongiform encephalopathy in cattle. Vet Rec 1987, 121:419-420.

2. Prusiner SB: Molecular biology of prion diseases. Science 1991, 252:1515-1522.

3. Jacobs JG, Langeveld JP, Biacabe AG, Acutis PL, Polak MP, Gavier-Widen D, Buschmann A, Caramelli M, Casalone C, Mazza M, Groschup M, Erkens JH, Davidse A, van Zijderveld FG, Baron T: Molecular discrimination of atypical bovine spongiform encephalopathy strains from a geographical region spanning a wide area in Europe. J Clin Microbiol 2007, 45:1821-1829.

4. Biacabe AG, Laplanche $\mathrm{J}$, Ryder $\mathrm{S}$, Baron T: Distinct molecular phenotypes in bovine prion diseases. EMBO Rep 2004, 5:110-115.

5. Casalone C, Zanusso G, Acutis P, Ferrari S, Capucci L, Tagliavini F, Monaco S, Caramelli M: Identification of a second bovine amyloidotic spongiform encephalopathy: molecular similarities with sporadic Creutzfeldt-Jakob disease. Proc Natl Acad Sci USA 2004, 101:3065-3070.

6. Baron T, Biacabe AG, Arsac JN, Benestad S, Groschup MH: Atypical transmissible spongiform encephalopathies (TSEs) in ruminants. Vaccine 2007, 25:5625-5630.

7. Biacabe AG, Morignat E, Vulin J, Calavas D, Baron TG: Atypical bovine spongiform encephalopathies, France, 2001-2007. Emerg Infect Dis 2008, 14:298-300.

8. Brown P, MCShane LM, Zanusso G, Detwile $L$ : On the question of sporadic or atypical bovine spongiform encephalopathy and Creutzfeldt-Jakob disease. Emerg Infect Dis 2006, 12:1816-1821.

9. Clawson ML, Richt JA, Baron T, Biacabe AG, Czub S, Heaton MP, Smith TP, Laegreid WW: Association of a bovine prion gene haplotype with atypical BSE. PLoS One 2008, 3:e1830.

10. Gavier-Widén D, Nöremark M, Langeveld JP, Stack M, Biacabe AG, Vulin J, Chaplin M, Richt JA, Jacobs J, Acín C, Monleón E, Renström L, Klingeborn B, Baron TG: Bovine spongiform encephalopathy in Sweden: an H-type variant. J Vet Diagn Invest 2008, 20:2-10.

11. Richt JA, Hall SM: BSE case associated with prion protein gene mutation. PLoS Pathog 2008, 4:e1000156.

12. Dudas S, Yang J, Graham C, Czub M, McAllister TA, Coulthart MB, Czub S: Molecular, biochemical and genetic characteristics of BSE in canada. PLoS One 2010, 5:e10638.

13. Buschmann A, Gretzschel A, Biacabe AG, Schiebel K, Corona C, Hoffmann C, Eiden M, Baron T, Casalone C, Groschup MH: Atypical BSE in Germanyproof of transmissibility and biochemical characterization. Vet Microbiol 2006, 117:103-116.

14. Baron TG, Biacabe AG, Bencsik A, Langeveld JP: Transmission of new bovine prion to mice. Emerg Infect Dis 2006, 12:1125-1128.

15. Baron T, Vulin J, Biacabe AG, Lakhdar L, Verchere J, Torres JM, Bencsik A Emergence of classical BSE strain properties during serial passages of $\mathrm{H}$ BSE in wild-type mice. PLoS One 2011, 6:e15839.

16. Béringue $V$, Bencsik $A$, Le Dur A, Reine $F$, Laï $T L$, Chenais N, Tilly G, Biacabé AG, Baron T, Vilotte $J$, Laude $H$ : Isolation from cattle of a prion strain distinct from that causing bovine spongiform encephalopathy. PLOS Pathog 2006, 2:e112.

17. Capobianco R, Casalone C, Suardi S, Mangieri M, Miccolo C, Limido L, Catania M, Rossi G, Di Fede G, Giaccone G, Bruzzone MG, Minati L, Corona C, Acutis P, Gelmetti D, Lombardi G, Groschup MH, Buschmann A, Zanusso G, Monaco S, Caramelli M, Tagliavini F: Conversion of the BASE prion strain into the BSE strain: the origin of BSE? PLOS Pathog 2007, 3: e31

18. Okada H, Masujin K, Imamaru Y, Imamura M, Matsuura Y, Mohri S, Czub S, Yokoyama T: Experimental transmission of H-type Bovine Spongiform Encephalopathy to bovinized transgenic mice. Vet Pathol 2011.

19. Lombardi G, Casalone C, D'Angelo A, Gelmetti D, Torcoli G, Barbieri I, Corona C, Fasoli E, Farinazzo A, Fiorini M, Gelati M, lulini B, Tagliavini F, Ferrari S, Caramelli M, Monaco S, Capucci L, Zanusso G: Intraspecies transmission of BASE induces clinical dullness and amyotrophic changes. PLOS Pathog 2008, 4:e1000075.

20. Balkema-Buschmann A, Ziegler U, Mclntyre L, Keller M, Hoffmann C, Rogers R, Hills B, Groschup MH: Experimental challenge of cattle with German atypical bovine spongiform encephalopathy (BSE) isolates. J Toxicol Environ Health A 2011, 74:103-109.

21. Fukuda $S$, Iwamaru $Y$, Imamura $M$, Masujin $K$, Shimizu $Y$, Matsuura $Y$, Shu $Y$, Kurachi M, Kasai K, Murayama Y, Onoe S, Hagiwara K, Sata T, Mohri S, Yokoyama T, Okada H: Intraspecies transmission of L-type-like Bovine Spongiform Encephalopathy detected in Japan. Microbiol Immunol 2009, 53:704-707.

22. Dobly A, Langeveld J, van Keulen L, Rodeghiero C, Durand S, Geeroms R, Van Muylem P, De Sloovere J, Vanopdenbosch E, Roels S: No H- and L-type cases in Belgium in cattle diagnosed with bovine spongiform encephalopathy (1999-2008) aging seven years and older. BMC Vet Res 2010, 6:26. 
23. Fraser H, Bruce ME, Chree A, McConnell I, Wells GA: Transmission of bovine spongiform encephalopathy and scrapie to mice. J Gen Virol 1992, 73:1891-1897.

24. Richt JA, Kunkle RA, Alt D, Nicholson EM, Hamir AN, Czub S, Kluge J, Davis AJ, Hall SM: Identification and characterization of two bovine spongiform encephalopathy cases diagnosed in the United States. J Vet Diagn Invest 2007, 19:142-154.

25. Stack M, Focosi-Snyman R, Cawthraw S, Davis L, Jenkins R, Thorne L, Chaplin M, Everitt S, Saunders G, Terry L: Two unusual bovine Spongiform encephalopathy cases detected in Great Britain. Zoonoses Public Health 2009, 56:376-383.

26. Polak MP, Zmudzinski JF, Jacobs JG, Langeveld JP: Atypical status of bovine spongiform encephalopathy in Poland: a molecular typing study. Arch Virol 2008, 153:69-79.

27. Polak MP, Zmudzinski JF: Distribution of a pathological form of prion protein in the brainstem and cerebellum in classical and atypical cases of bovine spongiform encephalopathy. Vet J 2011.

28. Taylor DM, Brown JM, Fernie K, McConnell I: The effect of formic acid on BSE and scrapie infectivity in fixed and unfixed brain-tissue. Vet Microbiol 1997, 58:167-174.

29. Simmons MM, Harris P, Jeffrey M, Meek SC, Blamire IW, Wells GA: BSE in Great Britain: consistency of the neurohistopathological findings in two random annual samples of clinically suspect cases. Vet Rec 1996, 138:175-177.

30. Sai $S$, Hayama M, Hotchi M: A new amyloid stain by phenol Congo red. Pathol Clin Med 1986, 4:1229-1232, (in Japanese).

31. Okada H, Sato Y, Sata T, Sakurai M, Endo J, Yokoyama T, Mohri S: Antigen retrieval using sodium hydroxide for prion immunohistochemistry in bovine spongiform encephalopathy and scrapie. J Comp Pathol 2011, 144:251-256.

32. Shimizu Y, Kaku-Ushiki Y, Iwamaru Y, Muramoto T, Kitamoto T, Yokoyama T, Mohri S, Tagawa Y: A novel anti-prion protein monoclonal antibody and its single-chain fragment variable derivative with ability to inhibit abnormal prion protein accumulation in cultured cells. Microbiol Immunol 2010, 54:112-121.

33. Kim CL, Karino A, Ishiguro N, Shinagawa M, Sato M, Horiuchi M: Cellsurface retention of PrPC by anti-PrP antibody prevents proteaseresistant PrP formation. J Gen Virol 2004, 85:3473-3482.

34. Horiuchi M, Yamazaki N, Ikeda T, Ishiguro N, Shinagawa M: A cellular form of prion protein (PrPC) exists in many non-neuronal tissues of sheep. $J$ Gen Virol 1995, 76:2583-2587.

35. Takahashi H, Takahashi RH, Hasegawa H, Horiuchi M, Shinagawa M, Yokoyama T, Kimura K, Haritani M, Kurata T, Nagashima K: Characterization of antibodies raised against bovine-PrP-peptides. J Neurovirol 1999, 5:300-307

36. Shimada K, Hayashi HK, Ookubo Y, Iwamaru Y, Imamura M, Takata M, Schmerr MJ, Shinagawa M, Yokoyama T: Rapid PrP(Sc) detection in lymphoid tissue and application to scrapie surveillance of fallen stock in Japan: variable $\operatorname{PrP}(\mathrm{Sc})$ accumulation in palatal tonsil in natural scrapie. Microbiol Immunol 2005, 49:801-804.

37. Hills D, Comincini S, Schlaepfer J, Dolf G, Ferretti L, Williams JL: Complete genomic sequence of the bovine prion gene (PRNP) and polymorphism in its promoter region. Anim Genet 2001, 32:231-232.

38. Seuberlich T, Botteron C, Wenker C, Café-Marçal VA, Oevermann A, Haase B, Leeb T, Heim D, Zurbriggen A: Spongiform encephalopathy in a miniature zebu. Emerg Infect Dis 2006, 12:1950-1953.

39. Wells GA, Wilesmith JW, McGill IS: Bovine spongiform encephalopathy: a neuropathological perspective. Brain Pathol 1991, 1:69-78.

40. Vidal E, Marquez M, Tortosa R, Costa C, Serafin A, Pumarola M: Immunohistochemical approach to the pathogenesis of bovine spongiform encephalopathy in its early stages. J Virol Methods 2006, 134:15-29.

41. Breslin P, McElroy M, Bassett $H$, Markey B: Vacuolar lesion profile of BSE in the Republic of Ireland. Vet Rec 2006, 159:889-890.

42. González L, Martin S, Houston FE, Hunter N, Reid HW, Bellworthy SJ, Jeffrey M: Phenotype of disease-associated PrP accumulation in the brain of bovine spongiform encephalopathy experimentally infected sheep. $J$ Gen Virol 2005, 86:827-838.

43. Sisó S, González L, Jeffrey M: Neuroinvasion in prion diseases: the roles of ascending neural infection and blood dissemination. Interdiscip Perspect Infect Dis 2010, 2010:747892.
44. Martin S, Jeffrey M, Gonzalez L, Siso S, Reid HW, Steele P, Dagleish MP, Stack MJ, Chaplin MJ, Balachandran A: Immunohistochemical and biochemical characteristics of BSE and CWD in experimentally infected European red deer (Cervus elaphus elaphus). BMC Vet Res 2009, 5:26.

45. Miyazono M, Iwaki T, Kitamoto T, Kaneko Y, Doh-ura K, Tateishi J: A comparative immunohistochemical study of Kuru and senile plaques with a special reference to glial reactions at various stages of amyloid plaque formation. Am J Pathol 1991, 139:589-598.

46. Hagiwara K, Yamakawa $Y$, Sato $Y$, Nakamura $Y$, Tobiume M, Shinagawa M, Sata T: Accumulation of mono-glycosylated form-rich, plaque-forming PrPSc in the second atypical bovine spongiform encephalopathy case in Japan. Jpn J Infect Dis 2007, 60:305-308.

47. Jeffrey M, Martin S, Gonzalez L: Cell-associated variants of disease-specific prion protein immunolabelling are found in different sources of sheep transmissible spongiform encephalopathy. J Gen Virol 2003, 84:1033-1045.

48. Jeffrey M, Martin S, Gonzalez L, Ryder SJ, Bellworthy SJ, Jackman R: Differential diagnosis of infections with the bovine spongiform encephalopathy (BSE) and scrapie agents in sheep. J Comp Pathol 2001, 125:271-284.

49. Bencsik AA, Debeer SO, Baron TG: An alternative pretreatment procedure in animal transmissible spongiform encephalopathies diagnosis using PrPsc immunohistochemistry. J Histochem Cytochem 2005, 53:1199-1202.

50. Furuoka H, Yabuzoe A, Horiuchi M, Tagawa Y, Yokoyama T, Yamakawa Y, Shinagawa M, Sata T: Species-specificity of a panel of prion protein antibodies for the immunohistochemical study of animal and human prion diseases. J Comp Pathol 2007, 136:9-17.

51. Van Everbroeck B, Pals P, Martin JJ, Cras P: Antigen retrieval in prion protein immunohistochemistry. J Histochem Cytochem 1999, 47:1465-1470.

52. Baron T, Bencsik A, Biacabe AG, Morignat E, Bessen RA: Phenotypic similarity of transmissible mink encephalopathy in cattle and L-type bovine spongiform encephalopathy in a mouse model. Emerg Infect Dis 2007, 13:1887-1894.

53. Biacabe AG, Jacobs JG, Bencsik A, Langeveld JP, Baron TG: H-type bovine spongiform encephalopathy: complex molecular features and similarities with human prion diseases. Prion 2007, 1:61-68.

54. Lehmann S, Harris DA: Blockade of glycosylation promotes acquisition of scrapie-like properties by the prion protein in cultured cells. J Biol Chem 1997, 272:21479-21487.

55. Priola SA, Lawson VA: Glycosylation influences cross-species formation of protease-resistant prion protein. Embo J 2001, 20:6692-6699.

56. Piro JR, Harris BT, Nishina K, Soto C, Morales R, Rees JR, Supattapone S Prion protein glycosylation is not required for strain-specific neurotropism. J Virol 2009, 83:5321-5328.

57. Stumpf MP, Krakauer DC: Mapping the parameters of prion-induced neuropathology. Proc Natl Acad Sci USA 2000, 97:10573-10577.

58. Nicholson EM, Brunelle BW, Richt JA, Kehrli ME Jr, Greenlee JJ: Identification of a heritable polymorphism in bovine PRNP associated with genetic transmissible spongiform encephalopathy: evidence of heritable BSE. PLoS One 2008, 3:e2912.

59. Manuelidis L: Transmissible encephalopathy agents: virulence, geography and clockwork. Virulence 2010, 1:101-104.

doi:10.1186/1297-9716-42-79

Cite this article as: Okada et al:: Experimental H-type bovine spongiform encephalopathy characterized by plaques and glial- and stellate-type prion protein deposits. Veterinary Research 2011 42:79. 